\title{
Educação em sociedades complexas: desafios para ressignificar sociopedagógica e politicamente a escola
}

\author{
Telmo Marcon \\ Consuelo Cristine Piaia \\ Universidade de Passo Fundo
}

\section{Resumo}

0 presente artigo, de natureza bibliográfica, propõe-se a refletir sobre a educação no contexto das sociedades complexas, tendo, como delimitação, a ressignificação da escola. 0 texto inicia problematizando as sociedades complexas, para, em seguida, questionar os limites do modelo de ciência que se tornou hegemônico e analisar duas tradições pedagógicas que influenciaram profundamente a educação formal: a tradicional e a moderna. Por fim, serão feitas referências à escola itinerante do MST, enquanto experiência de educação, que possibilita superar a dicotomia escola e sociedade, bem como traz elementos para a ressignificação da escola frente aos desafios postos pelas sociedades complexas.

Palavras-chave: Educação. Escola. Sociedades complexas. Pedagogia tradicional. Pedagogia moderna. 


\section{Education in complex societies: challenges to reframe the school socio-educationally and politically}

This bibliographic paper proposes to reflect on education in the context of complex societies, placed within the reframing of the school. The text begins by problematizing complex societies, to then question the limits of the science model that has become hegemonic and analyze two pedagogical traditions that have deeply influenced formal education: the traditional and the modern. Lastly, we will refer to the itinerant school of MST, as an education experience that allows for overcoming the school-and-society dichotomy, which also brings new elements to reframe the school in face of the challenges set by complex societies.

Keywords: Education.School.Complex societies.Traditional pedagogy. Modern pedagogy.

\section{La educación en sociedades complejas: retos para resignificar sociopedagógica y políticamente la escuela}

El presente artículo, de naturaleza bibliográfica, propone reflexionar acerca de la educación formal en el contexto de las sociedades complejas, teniendo como delimitación la resignificación de la escuela. El texto comienza problematizando las sociedades complejas, y así cuestionar los límites del modelo de ciencia que se tornó hegemónico y analizar dos tradiciones pedagógicas que han influenciado profundamente la educación formal: la tradicional y la moderna. Por fin, se hacen referencias a la escuela itinerante del MST como experiencia de educación que posibilita superar la dicotomía escuela y sociedad, además de traer elementos para la resignificación de la escuela ante los desafíos puestos por las sociedades complejas.

Palabras-clave: Educación. Escuela. Sociedades complejas. Pedagogía tradicional. Pedagogía moderna. 


\section{Considerações iniciais}

Crescem as avaliações de que a escola não está conseguindo, de um modo geral, responder positivamente aos desafios emergentes na sociedade contemporânea. Os diagnósticos e as alternativas propostos para a superação desses desafios são diversos e enfocam distintas questões: metodologia, currículo, novas disciplinas, avaliação, políticas educacionais adequadas, maiores investimentos públicos, entre outros. Sem desconsiderar a pertinência dessas questões, pretende-se discutir outras. Para tanto, o texto inicia com uma reflexão sobre sociedades complexas, segue com uma análise sobre as pedagogias tradicional e moderna, do ponto de vista das relações escola e sociedade, para concluir com algumas considerações sobre experiências de educação não formal e suas potencialidades para ressignificar a escola.

0 primeiro esforço, portanto, foca-se numa reflexão sobre as "sociedades complexas". A complexidade é imanente e específica da sociedade contemporânea? Depende de referenciais teórico-epistemológicos? Em que condições é possível falar de sociedades complexas? Que elementos a definem e caracterizam no contexto atual?

Em diferentes contextos históricos, foram experienciadas situações novas que questionaram valores, práticas e tradições consolidadas de períodos precedentes: os impactos da reflexão filosófica na Grécia Antiga, por exemplo; as descobertas científicas na modernidade; as pesquisas antropológicas que mostraram as complexas estruturas de parentesco em sociedades aparentemente simples; as relações socioeconômicas e culturais estabelecidas por conquistadores; as transformações de conhecimentos em tecnologias; as crises nas formas tradicionais de pensar e a emergência de um pensamento pós-metafísico; as contemporâneas transformações econômicas; as novas tecnológicas de comunicação; etc. Os impactos dessas transformações foram distintos nos diferentes contextos, mas se pode dizer que, ao se apresentarem como novos, tornaram complexas as sociedades em relação ao que precedia. Evidentemente as transformações em curso na atualidade ganham proporções diferenciadas pelas características específicas desse contexto, entre as quais o encurtamento de tempos e espaços mediante tecnologias que agilizam significativamente a circulação de informações, com profundos impactos sociais, econômicos, políticos e culturais, bem como o acesso a determinadas informações até então impensáveis ou que demandavam muito tempo e altos investimentos. Esses elementos tornam a sociedade atual complexa e diferenciam-na de outros períodos. 


\section{Problematizando o conceito de sociedades complexas}

As transformações em curso na sociedade atual aprofundam a consciência da incapacidade de dominarmos todos os conhecimentos e experiências colocados à disposição. Multiplicam-se referenciais e paradigmas no âmbito das ciências e dos conhecimentos em geral. Mesmo que muitos desses referenciais sejam questionados e questionáveis, não há como negar que eles existem e possuem defensores. Estão emergindo novos elementos que se agregam à pluralidade de opções teórico-metodológicas existentes na construção de conhecimentos e na apreensão e seleção da realidade. A crise de paradigmas e das explicações totalizantes abriu espaços para um olhar caleidoscópico. Essas transformações provocam um duplo movimento: de um lado, o reconhecimento de que a realidade é complexa e, de outro, que os novos referenciais buscam dar conta das múltiplas expressões dos fenômenos.

A complexidade que se expressa teoricamente na crise dos paradigmas é, também, ao mesmo tempo, empírica e adentra as instituições sociais, entre elas, a escola, com todas as implicações didáticas, pedagógicas, políticas, curriculares, as relações com a sociedade, etc. A crescente multiplicação de espaços educativos, para além da escola, as novas formas de socialização e individualização, os valores emergentes, os novos questionamentos, as rupturas com determinadas tradições, a constituição de novas relações sociais e familiares, novos enfoques para questões de gênero e de identidade, a afirmação da diversidade multicultural e os desafios da educação intercultural, entre outros, estão exigindo que o fazer pedagógico escolar, bem como a formação de educadores sejam ressignificados. As rupturas com determinadas explicações metafísicas, próprias de um modo fechado de pensar, rigidamente hierarquizado e linear, com verdades estabelecidas e no qual a autoridade encontra-se bem localizada em figuras como o pai, o padre, o professor, o prefeito, etc., convive e se confronta com formas pós-metafísicas próprias de uma racionalidade falibilista, que se alimenta da tolerância à dúvida, questionando o dogmatismo e o fundamentalismo.

Ao tratar de sociedades complexas, é necessário, portanto, problematizar em que dimensões expressa-se a complexidade e o que distingue o contexto atual de outros períodos históricos. Argumentamos que a complexidade da sociedade, num dado período, está vinculada às realidades emergentes, aos referenciais teóricos e epistemológicos existentes e às perguntas formuladas. Dependendo dos referenciais utilizados, fenômenos complexos podem ser simplificados. Buscando fundamentar essa tese, serão tecidas algumas considerações, a título de ilustração, sobre a mitologia e dois autores clássicos que pesquisaram 
diferentes contextos: Umberto Eco, (1986) no período medieval, e Carlos Ginzburg (2002), no início do período moderno.

Uma rápida incursão pela mitologia, especialmente a grega, permite vislumbrar um conjunto de questões emergentes das narrativas que apontam para contextos socioculturais, políticos, pedagógicos, enigmáticos e simbólicos altamente complexos. Não se trata apenas das respostas dadas aos diferentes fenômenos físicos, antropológicos e existenciais, ou mesmo problemas sociopolíticos, mas atentar para as questões que foram formuladas em distintos contextos da sociedade grega. 0 olhar da mitologia permite inferir que a sociedade grega não é simples, ou seja, é extremamente complexa, e a mitologia reforça essa conclusão.

A mitologia tematiza, numa linguagem que the é peculiar, questões sociais, políticas, culturais, econômicas, subjetivas, sentimentais. Deuses disputam espaços de poder entre si e com os homens. A vingança é um instrumento de punição aos que ousam quebrar regras. Questões envolvendo amor, beleza, sentimentos perpassam as relações. As narrativas reforçam hierarquias que não podem ser quebradas. Rituais atualizam desejos e projetam fartura. Os grandes enigmas que perpassam a criação e o destino dos humanos instigam a imaginação. Como é possível dizer que tudo isso não é expressão de uma sociedade complexa? Podemos considerar, como o fez Augusto Comte (1978, p. 4), que a mitologia não passa de um estágio da humanidade, já superado. Podemos pensar em outras direções e reconhecer que a mitologia é uma forma de encarar o mundo e de explicá-lo em suas múltiplas dimensões. As respostas que foram dadas naqueles contextos é que podem ser questionadas. A simplificação de um dado contexto decorre, em parte, de explicações apressadas que, ao mesmo tempo que dão conta de determinadas dimensões dos fenômenos sociais, negligenciam tantas outras.

Uma análise criteriosa da obra "O nome da Rosa" de Eco (1986) leva-nos a superar a ideia de que a sociedade medieval era simples. 0 mesmo se pode dizer de Ginzburg (2002) na obra "0 queijo e os vermes: o cotidiano e as ideias de um moleiro perseguido pela Inquisição", em relação ao contexto sociocultural onde vive Menocchio (1532-1599), essencialmente rural. Esse personagem questiona determinados dogmas e formula novas ideias sobre a criação do mundo e questões religiosas que colidem com as explicações dominantes, fato que resulta na sua própria condenação à morte. Os detalhes que Ginzburg extrai dos documentos do período em que viveu o personagem revelam um cotidiano extremamente complexo. As complexas relações e tramas presentes nas obras de Eco e de Ginzburg, para dar apenas dois exemplos, evidenciam a capacidade de os autores adentrarem profundamente determinados contextos 
e apreenderem inúmeros elementos que são negligenciados ou simplesmente desconhecidos por outros pesquisadores que se debruçaram sobre os mesmos temas e contextos.

Os exemplos dessas duas obras, bem como a questão da mitologia, justificam-se como fundamentação da tese de que as sociedades nunca foram simples; a simplificação está diretamente relacionada aos referenciais teóricos e metodológicos que utilizamos e a capacidade ou ausência dela em questionar em profundidade os fenômenos. Muitas explicações sobre as realidades socioculturais, políticas e econômicas existentes na atualidade não levam em conta a complexidade. Explicações deterministas tendem sempre a tomar uma dimensão do real como sendo o todo dos fenômenos e processos e, dessa forma, não conseguem dar conta das complexas relações que se entrecruzam nas experiências e nas práticas sociais. A ciência que se tornou hegemônica, conforme Santos (1989; 2004) e Santos e Meneses (2010), contribuiu para essa simplificação.

O modelo de ciência assentado no paradigma positivista permitiu avanços importantes em determinadas dimensões dos fenômenos, mas, ao mesmo tempo, simplificou demasiadamente a realidade. No campo da sociologia, as preocupações de Durkheim (1978, 1990), por exemplo, apontam para três características dos fatos sociais, objetos da sociologia: regularidade, universalidade e coerção. Ao mesmo tempo que esses pressupostos permitiram avanços importantes na constituição de um campo de investigação, no caso da sociologia, criaram um conjunto de obstáculos ao avanço, especialmente para a sociologia da educação. Dentro desse constructo, não há espaços para a subjetividade e as diferentes formas de subjetivação. Essas dimensões, segundo Durkheim, fogem ao campo de investigação da sociologia e, portanto, não fazem parte de seu objeto.

Para Santos e Meneses (2010, p. 21), o paradigma que se tornou hegemônico na ciência moderna primou pela padronização de critérios de validade científica, tendo as ciências físico-naturais como referência. "Sendo um modelo global, a nova racionalidade cientifica é também um modelo totalitário, na medida em que nega o caráter racional e todas as formas de conhecimento que se não pautarem pelos seus princípios epistemológicos e pelas suas regras metodológicas".

A ciência sempre se esforçou em conhecer a realidade. Para tanto, foram formulados paradigmas, referenciais epistemológicos, critérios de validade e procedimentos metodológicos. 0 problema não reside nesses processos, mas na simplificação das perguntas formuladas em relação aos fenômenos sociais e físico-naturais investigados. A crescente fragmentação dos fenômenos em partes, já preanunciada por Descartes na obra “Discursos do Método" (2003), 
e a especialização daí decorrente contribuíram para o empobrecimento do conhecimento sobre a realidade. Não que a realidade tenha se tornado mais simples, mas a ciência dominante é que produziu e, em parte, continua a produzir essa simplificação.

Quais as possibilidades de superação desse reducionismo? Em primeiro lugar, é fundamental admitir que os fenômenos socioculturais, políticos, econômicos e educacionais sempre foram complexos, dentro das características próprias de cada contexto histórico. Talvez, hoje, possamos dizer que determinados contextos eram menos complexos que os atuais, mas fazemos isso a partir de determinadas compreensões e instrumentos de que dispomos na atualidade. Hoje, existe um conjunto de novos elementos que são resultantes das transformações econômicas, políticas, socioculturais e tecnológicas em curso. Em segundo, é fundamental a construção e a apropriação de referenciais que concebam o real na sua complexidade; ou seja, não existem respostas simples e imediatas para questões complexas que, mesmo com todo o esforço empreendido, sempre permitem ir além. Fenômenos socioeducacionais não podem ser reduzidos à quantificação. Em terceiro, há a necessidade de estabelecer critérios que possibilitem pensar as várias dimensões que constituem os fatos sociais, superando, assim, as dicotomias entre objetividade e subjetividade.

Após analisar a constituição e a ciência que se tornou hegemônica, bem como da crise paradigmática que estamos vivendo, Santos e Meneses (2010, p. 6192) formulam quatro teses que apontam e justificam a emergência de um novo paradigma: al todo conhecimento científico-natural é científico-social; b) todo conhecimento é local e total; cl todo conhecimento é autoconhecimento; d) todo conhecimento científico visa a constituir-se num novo senso comum. Assim, abrem-se possibilidades para a superação da dicotomia entre as ciências sociais e as ciências naturais, valorizando a diversidade de conhecimentos, excluídos pelo paradigma dominante por não atender ao critério de universalidade. Por conseguinte, questiona-se a pretensa neutralidade do pesquisador e os resultados de suas investigações. Essa crítica parte da compreensão de que o pesquisador não apenas manuseia instrumentos para produzir conhecimentos, mas participa desse processo, fazendo escolhas. Como dizem Santos e Meneses, o conhecimento é contextualizado e, por isso mesmo, ganha universalidade (2010, p. 16). A questão da neutralidade não se restringe ao campo da ciência, mas se estende para a educação e para as práticas institucionais, no caso, a escola. Essa questão será aprofundada na parte final do artigo, visto que a dimensão política é fundamental para a ressignificação da escola.

Em síntese, as justificativas apresentadas até aqui dão conta de que a complexidade do real depende, em parte, da profundidade de nossas 
interrogações, dos paradigmas que referenciam as pesquisas e dos recursos metodológicos utilizados. É evidente que as transformações que ocorreram de modo especial, nas últimas três décadas, impactam profundamente os fatos e as práticas sociais e colocam novos desafios para as investigações. Ou seja, existem questões que desafiam as novas relações sociais, as interações e os processos de socialização. Há interferências de tecnologias, especialmente a televisão, o computador e a internet, a telefonia celular, a indústria de insumos químicos, a automobilística e a aviação, que ainda não foram suficientemente avaliadas, e, num certo sentido, ainda não é possível dimensionar todas as consequências. Mesmo assim, é possível formular algumas hipóteses que apontam para os impactos que essas tecnologias vêm produzindo em todas as dimensões da vida e alterando profundamente tradições, costumes, relações, identidades, formas de socialização e valores. É preciso tempo para que análises mais profundas e amplas possam ser desenvolvidas. Por exemplo, como os recursos tecnológicos estão produzindo novos padrões estéticos, de consumo, hábitos alimentares, tendências de moda, novas formas de socialização? Como a socialização que envolve relações e compartilhamento de valores está ocorrendo, paradoxalmente, em espaços privados? Até que ponto as instituições educativas de maior tradição, como a família e a escola, estão conseguindo compreender essas transformações e colocando-se na condição de sujeito da socialização?

Nos processos de transformações, nas formas de socialização, no encurtamento dos espaços por meio das tecnologias e nas mudanças radicais de tempo, emergem novos sujeitos coletivos que foram, historicamente, silenciados, conforme reflexões de Benjamin (1994, p. 222-332), entre os quais se destacam mulheres, negros, indígenas, homossexuais, minorias étnicas, etc. Pesquisas e discussões sobre multiculturalidade e intercultura desafiam as práticas pedagógicas e as políticas educacionais. 0 conceito de diversidade ganha centralidade nas novas elaborações teóricas e desafia paradigmas homogeneizadores e, fortemente, a pedagogia tradicional. Quais as implicações teóricas e pedagógicas decorrentes da entrada em cena desses novos sujeitos?

No mundo do trabalho, estão em curso inúmeras e profundas transformações. Evidentemente, nem todas elas podem ser reduzidas à luz do paradigma da sociedade do conhecimento, mas não se pode negar que as transformações estão ocorrendo. Ricardo Antunes (1999, 2005, 2009), entre outros, vem analisando as metamorfoses no mundo do trabalho em decorrência das novas relações de produção e das mudanças produzidas pela globalização e pelas novas tecnologias. Essas metamorfoses não são de simples compreensão, especialmente pelas novas interpretações que estão sendo feitas. Não dá para 
negar que está havendo um crescente apelo ao consumo, decorrente das novas técnicas que permitem um aumento substancial na produção, mas também nas novas formas e meios de propaganda. Para Bauman, esses processos demarcam a passagem da sociedade da produção para uma sociedade do consumo. (2008, p. 37-69)

A definição de sociedades complexas passa, portanto, pelo reconhecimento da relevância dos referenciais epistemológicos, teóricos e metodológicos e da explicitação dos elementos emergentes, próprios do contexto atual. Do diálogo entre essas duas dimensões, torna-se possível construir diagnósticos capazes de apreender os elementos constitutivos das sociedades contemporâneas que permitam defini-las como complexas. Toda sociedade é complexa em seu contexto e exige do ser humano esforços para compreendê-la a fim de atuar nela como sujeito. De que forma as questões postas no contexto atual intervêm nas práticas sociais e nas instituições, especialmente a escola? Como a escola posiciona-se frente a essas transformações?

\section{As pedagogias tradicional e moderna na perspectiva da relação escola e sociedade}

Como as influentes pedagogias, moderna e tradicional, pensaram a relação escola e sociedade? Em que medida elas foram e são capazes de dar conta dos desafios postos pelas sociedades complexas? Para fundamentar essa análise, retoma-se a tese defendida por Bernard Charlot na obra "A Mistificação Pedagógica: realidades sociais e processos ideológicos na teoria da educação”, publicada na França, em 1976, traduzida e publicada no Brasil em 1979.

Uma primeira constatação é de que, no século XX, multiplicam-se as críticas ao papel da escola na sociedade. Funcionalistas, fenomenólogos, estruturalistas, entre outros, desferem críticas ao papel da escola acusando-a, segundo Charlot, de "ser ao mesmo tempo inadaptada à sociedade e demasiado bem adaptada a uma sociedade injusta" (1979, p. 150). As críticas relativas à inadaptação da escola em relação à sociedade destacam a sua atuação na transmissão de saberes fossilizada, baixa potência de informação, transmissão verbal antiquada, formação de uma elite, pouca vinculação com a formação profissional ou alienada das experiências e saberes construídos e vividos pelos alunos. De outro lado, é acusada de ser demasiadamente adaptada aos interesses sociais e econômicos dominantes, cuja ideologia dissemina. A partir dessas observações, Charlot questiona-se: a escola precisa isolar-se da sociedade ou meramente reproduzi-la? No seu entendimento (1979, p. 151-152), 
a relação com a sociedade é a chave para compreender o papel e o sentido das instituições sociais, entre elas a escola, voltadas à formação. Essa relação foi dicotomizada pelas pedagogias tradicional e moderna, mesmo que por razões distintas e por caminhos diferentes.

Para Charlot, a escola pode desempenhar um papel ideológico na sociedade na medida em que se distanciar das realidades socioculturais que fazem partem do contexto escolar. Desconsiderando os elementos do contexto, ela pode organizar sua própria estratégia educativa, justificando-a. Enquanto instituição fechada protege a criança da corrupção da vida social (1979, p. 154). A ideia de preparação para a vida adulta por meio de um "desvio cultural" que proteja a criança da sociedade é a proposta da pedagogia tradicional que tem, em Platão, um dos seus fundadores, mas também da pedagogia moderna que tem como pioneiro Jean Jacques Rousseau. Essas duas tradições pretendem proteger, por caminhos distintos, a criança da "corrupção" social, evitando ao máximo a influência social. Para cumprir este papel a escola enclausura-se, fazendo o mesmo com a criança. É importante reconstruir os argumentos que, segundo Charlot, fundamentam essas duas pedagogias.

\section{Pedagogia tradicional}

Muitas pesquisas já se encarregaram de investigar e criticar a pedagogia tradicional. Pretendemos, nos limites do artigo, destacar apenas alguns elementos. A pedagogia tradicional tem sua formulação primeira, segundo Charlot, em Platão. Ele parte do princípio da existência de uma essência préconstituída no ser humano que precisa de condições para sua realização. Dentro dessa tradição que ganha, ao longo da história, outras contribuições, entre as quais a da Companhia de Jesus, a realização da essência é

[...] atualizar em si o Homem ideal, de acordo com o Absoluto e a estrutura metafísica do universo. Para Platão, a essência humana é a alma enquanto capaz de aprender as Ideias, isto é, a alma em sua parte intelectual; a alma que contempla as ideias está de acordo com a estrutura de um Universo orientado segundo o eixo: sensívelinteligível [...] (Charlot, 1979, p. 59)

Platão parte da existência de um princípio metafísico, o Bem, a partir do qual deriva um conjunto de consequências políticas e pedagógicas. 0 fim da educação é alcançar o Bem. Para ele o homem nasce "corrompido", fato que implica a necessidade de um esforço para chegar ao Bem. A alma, ao não contemplar em profundidade o Bem, afasta-se dele, e a educação tem por função ajudar 
na realização dessa tarefa. No “mito da caverna”, Platão reforça essa ideia ao acentuar a necessidade de um movimento de libertação do mundo das trevas para ascender ao mundo da luz que, em outras palavras, significa a passagem de um estado de "corrupção" para um estado de perfeição. Nesse movimento, a mediação do social e da política cede lugar a um esforço de realização "pessoal" de um princípio já estabelecido como ponto de partida. Nesse sentido, a educação nada mais faz do que criar as condições para a realização de algo antecipadamente estabelecido. A não realização dessa essência passa a ser atribuída ao próprio Homem e à sua condição humana. A educação tem, portanto, um papel fundamental nesse movimento de redenção e de realização da própria essência. É dentro desse contexto que Charlot (1979, p. 45) fundamenta sua crítica à pedagogia tradicional e ao seu papel ideológico.

A pedagogia platônica desempenha um papel ideológico, camuflando por trás dos argumentos culturais a justificação das desigualdades sociais na divisão do trabalho: na cidade, somos artesão, guarda ou filósofo, mas porque cada um recebeu uma educação de acordo com as aptidões naturais.

Essa tradição pedagógica exerceu forte influência na educação escolar ocidental, especialmente quando incorporada pela tradição escolástica, mas principalmente pela Companhia da Jesus. A educação escolar é isolada da sociedade, portanto, despolitizada. 0 esforço empreendido pelos Jesuítas para sublimar os desejos e a concupiscência linclinação humana aos prazeres carnais em decorrência do pecado original, que, por sua vez, cria embaraços aos sentidos e à razãol por meio de um controle disciplinar rigoroso nos internatos, bem como da separação de meninos e meninas, conforme detalhado Ratio Studiorum (Franca, 1952), situa-se dentro desse horizonte pedagógico. Ao afastar as crianças do convívio mundano, a educação poderia criar as condições para a realização da essência divina. Os pressupostos dessa pedagogia, formulados inicialmente por Platão, bem como seus desdobramentos na tradição cristã ocidental são muito complexos e demandariam outras discussões que extrapolam os limites do presente texto.

\section{Pedagogia moderna}

A pedagogia moderna tem como marco fundador Rousseau. Sua obra política e pedagógica é extensa e complexa. Não há aqui nenhuma pretensão de reconstruir os argumentos fundamentais de sua obra, apenas sistematizar, a partir da contribuição de Charlot, alguns elementos que permitem fundamentar 
uma crítica aos limites da sua concepção pedagógica em relação à sociedade. Em 1757, Rousseau torna pública a obra "Do contrato social". Nela, afirma que "O homem nasce livre, e por toda a parte encontra-se a ferros". Defende a tese de que a ordem social não é natural, mas fruto de convenções, em que a família é a mais antiga dessas convenções (Rousseau, 1987, p. 22). Para ele, existe uma condição natural dos homens que é de felicidade, virtude e liberdade, que é destruída e apagada pela civilização.

Para Charlot, as pedagogias tradicional e moderna fundamentam-se em princípios metafísicos: para Platão, conforme já observado, é a ideia de Bem e, para Rousseau, é a ideia de Natureza. Rousseau critica os pressupostos metafísicos da pedagogia tradicional, mas a introdução do conceito de natureza incorre no mesmo problema. Sua concepção é de que os problemas sociais (corrupção) não são de ordem natural e sim criados pela sociedade. Dessa concepção decorrem importantes implicações políticas e pedagógicas, entre as quais a necessidade de afastar as crianças o máximo possível das influências sociais, e, para tanto, é fundamental a criação de condições para que permaneçam no estado de natureza.

A proposta pedagógica de Rousseau é, portanto, que a criança permaneça no estado de natureza. Para ele, "o homem é liberdade e a cultura deve estabelecer na sociedade a liberdade civil, equivalente social da liberdade natural do homem. De maneira geral, na pedagogia, a educação não muda o homem, permite-lhe somente tornar-se o que é..." (Charlot, 1979, p. 59). Para Rousseau a natureza é boa, ao contrário da tradição platônica e cristã para a qual a natureza é corrompida. Segundo Rousseau, a permanência no estado de natureza é condição fundamental para a realização humana. A respeito diz Charlot que o Emílio "é educado num meio extremamente pouco socializado", além de que seu preceptor tem a função de filtrar, controlar "cuidadosamente toda influência social" (1979, p. 47). A divisão do trabalho decorrente da propriedade privada gera desigualdades e introduz a corrupção. Nesse sentido, manter-se no estado de natureza é condição fundamental para evitar a corrupção. Para Charlot (1979, p. 48), Rousseau procura “reinstaurar na sociedade, graças à educação, a independência de que o homem se beneficiava antes que se instituísse a divisão do trabalho". As duas grandes tradições pedagógicas iniciadas por Platão e por Rousseau pensam a educação em contraposição à sociedade. Decorre daí a subordinação da sociedade aos determinantes metafísicos. Charlot (1979, p. 6364) faz a seguinte reflexão a respeito:

Mas se, verdadeiramente, a natureza humana fosse inalienável, o homem não teria necessidade de educação: é preciso, portanto, colocar que a natureza humana foi corrompida. Mas, ao mesmo tempo, não se pode renunciar à ideia de natureza 
humana inalienável, conceito-chave para considerar a educação como cultura e sem referência à realidade social; a pedagogia deve, portanto, desdobrar a natureza humana, e afirmar, ao mesmo tempo, que ela é inalienável e que foi corrompida.

Como veremos na sequência, decorre dessa compreensão uma necessária dicotomia entre educação e sociedade. Por conseguinte, a educação é despolitizada com todas as implicações daí decorrentes.

\section{Consequências das premissas postas pelas pedagogias tradicional e moderna}

A conclusão a que chega Charlot é de que a pedagogia tradicional e a moderna produzem um distanciamento em relação à sociedade. Dessa forma, ambas fundamentam pedagogias que descontextualizam os processos educativos da sociedade, dificultando uma compreensão das relações sociais, econômicas e políticas que perpassam o cotidiano dos sujeitos e das escolas (Charlot, 1979, p. 157-159). Para o autor, a escola é ideológica não quando transmite modelos sociais e seus ideais, mas quando os camufla por meio de um desvio cultural (1979, p.214-216), ou seja, quando não problematiza a educação no âmbito da sociedade.

A pedagogia tradicional clausurou a escola. Não apenas segregou crianças, adolescentes e jovens como se estruturou de tal modo que seus conteúdos ficaram isolados das questões sociais. A pedagogia centrada no professor impediu a fala do aluno e, ao desqualificar suas experiências, reforçou essa distância. Ao proteger a criança da corrupção advinda da sociedade ou da própria natureza humana, combateu os impulsos naturais e desconsiderou os educandos. Não é por acaso que o aluno é visto como objeto do conhecimento pela pedagogia tradicional. Para essa pedagogia, a apropriação cultural é resultante de um esforço pessoal, visto ser compreendida como fenômeno individual. Essa concepção faz-se muito presente na organização escolar e é visível quando "na classe, a criança está só, em face do saber e dos modelos, embora mantenha uma relação privilegiada com o mestre" (Charlot, 1979, p. 164). A sala de aula, dentro dessa concepção pedagógica, é organizada de trás para frente:

Na frente, o mestre, empoleirado em seu estrado, que the permite ver cada um e ser visto por cada um, e dispondo do quadro negro sobre o qual escreve a verdade. Em face do mestre, as crianças, que não são separadas dele senão por costas; assim se realiza materialmente o face a face do mestre e da verdade com cada criança, vendo cada um apenas o mestre. 
0 mestre representa a verdade e cada criança tem um importante papel pedagógico de ser o melhor, ou seja, estimula a competição. A pedagogia tradicional está apoiada num ideal de "elevação cultural" por meio da diferenciação. A disputa é a mola mestra. Embutida neste ideal está a ideia de que todos podem vencer desde que haja boa vontade e disciplina, que se traduz em obediência ao mestre, na organização do trabalho e no "controle corporal". A disciplina é a "regra básica de organização da escola tradicional" e a ausência dela considera-se falta de educação e obstáculo para a elevação ao absoluto. (Charlot, 1979, p. 167-168)

A pedagogia moderna, por sua vez, também se apoia no princípio de respeito às necessidades individuais e nos interesses naturais da criança. Daí a necessidade de criar um ambiente favorável à criança, o mais próximo da sua condição natural, que terá de ser diferente do mundo social dos adultos. A pedagogia moderna previne-se da corrupção social. A criança é boa e o adulto (sociedade) corrompe-a. Por isso, a estrutura relacional da pedagogia moderna diferencia-se da tradicional. Ela não privilegia a relação mestre e criança, mas se centra no desabrochar das possibilidades individuais por meio das relações com as outras crianças (grupo-classe) e com a realidade que se dá de forma privilegiada, mediante a atividade de pesquisa. 0 mestre não é o dono do saber, como propugna a pedagogia tradicional, mas o organizador das atividades e o estimulador dos alunos para expressarem seus desejos, sentimentos e imaginação. Os tempos e espaços são organizados a partir das necessidades e interesses dos alunos. As filas são substituídas por outras formas de organização grupal que possibilitam uma maior interação.

Apesar das diferenças pedagógicas, a tradicional e a moderna têm em comum, segundo Charlot, a supressão da "dimensão sócio-política da educação" (1979, p. 173). A pedagogia tradicional dá a resposta sem formular a pergunta. Mais que isso, traz respostas prontas a perguntas ou problemas "que não corresponde a nenhuma pergunta da criança” (Charlot, 1979, p. 177). A pedagogia moderna, por sua vez, destaca o papel das perguntas, mas não dá tanto valor às respostas ou à qualidade delas. Busca construir a experiência por meio da emoção, experimentação e observação. Contudo, não problematiza a experiência que, por si só, não significa construção de conhecimento. A superação dos limites da tradição moderna está, segundo Saviani (1989), no reconhecimento de que a experiência (prática social) constitui-se num ponto de partida, mas não num ponto de chegada.

Com base nos argumentos apresentados até aqui, é possível afirmar que as pedagogias tradicionais e modernas não contemplam o sentido e as relações com o saber e, por isso, a escola tem enormes dificuldades em mobilizar o 
aluno. Para Charlot, o prazer, o desejo e a paixão de estudar são elementos fundamentais da vida escolar. A mobilização é um pressuposto fundamental de qualquer proposta pedagógica crítica. Não é suficiente, diz, motivar o aluno a estudar, mas ele precisa estar mobilizado.

Não gosto muito dessa ideia de motivar os alunos, porque muitas vezes esse ato de motivar é o mesmo que enrolar os alunos para que eles façam alguma coisa que não estão a fim de fazer. 0 problema não é de motivação, mas de mobilização, que é coisa muito diferente. A motivação é externa, ao passo que a mobilização é um fenômeno interno: motiva-se alguém de fora, ao passo que se mobiliza a si mesmo de dentro. (Charlot, 2009, p. 83)

Ao não considerar a diversidade de experiências e de culturas, nem desenvolver um espírito crítico, a escola legitima e reproduz a cultura dominante. A pedagogia tradicional produz exclusão ao negar a diversidade e ao não reconhecer 0 outro; a pedagogia moderna, por sua vez, produz um resultado similar ao focar o indivíduo e sua experiência peculiar. Para a pedagogia tradicional, as diferentes temporalidades não têm sentido, visto que a educação é concebida como "atualização da natureza humana que é eternamente a mesma". A noção de criança como "adulto em miniatura" encontra, nessa tradição, a sua plena realização. Ao conceber a criança como igual, com base em sua natureza, camuflam-se as diferenças culturais, etárias e sociais.

A escola, na medida em que nega as múltiplas experiências que são construídas nos diferentes contextos socioculturais em que a criança está inserida, reforça as desigualdades sociais. Para Charlot, a pedagogia moderna concebe a escola como uma sociedade idealizada, eliminando sempre que possível o conflito. Ao abstrair os elementos políticos que se fazem presentes nas relações sociais e as diferentes condições econômicas, a escola contribui para uma educação ideológica. Cabe ressaltar que, para o autor, o conceito de ideologia é entendido como velamento de relações socioeconômicas e culturais contraditórias. Os conflitos e as diferenças existem e são constitutivas das realidades sociais e impactam nos processos socioculturais e educativos. 0 problema é que a tensão entre o indivíduo e a sociedade não pode ser compreendida de forma neutra. Quando não se consegue apreender o movimento contraditório da educação, a escola passa a ser pensada como um aparelho reprodutor da cultura dominante, como defenderam Bourdieu e Passeron (1982). Por não trabalharem com as contradições sociais, alguns teóricos apregoaram o "fim da escola", entre os quais Illich (1985). Mas abolir a escola resolve a opressão e a dominação de classe? Deixar a criança educar-se diretamente com a vida social dá-lhe condições de desenvolver capacidades para desvelar estas realidades? 
Charlot (1979) interroga sobre as possibilidades de a escola tornar-se um espaço de formação não ideológica. Uma escola não ideológica teria de sublinhar o caráter social da educação e as finalidades dos processos educativos. Nesse sentido, toda pedagogia precisa ser pensada como fenômeno sociopolítico, não neutro, ou seja, ordenada por fins sociais explícitos com o objetivo de desvelar o sistema social e repensar dialeticamente as relações escola e sociedade. Enquanto uma educação ideológica mascara as finalidades e os fenômenos sociopolíticos envolvidos nos processos educativos, uma educação não ideológica é constitutiva de processos que explicitam a sua dimensão política.

Após a discussão de alguns elementos de duas tradições pedagógicas clássicas, que se desdobram em várias outras tradições, cabe estabelecer os vínculos dessas críticas com as sociedades complexas. Qualquer tipo de resposta pedagógica positiva tem de dar conta, na atualidade, das complexas relações que se estabelecem entre sujeitos, grupos e classes sociais, bem como dos sujeitos e atores sociais emergentes que intervêm profundamente nos processos educativos, na socialização e na individualização. Não há, portanto, como dar conta dessas transformações em curso sem uma análise crítica e qualitativa das questões sociais, políticas, econômicas e culturais, postura que as pedagogias tradicional e moderna não dão conta. Na sequência, serão destacados alguns elementos emergentes de experiências de educação não formal que podem contribuir para uma educação não ideológica, além de dar conta dos desafios emergentes das sociedades complexas.

\section{Experiências de educação não formal e a ressignificação da escola}

A escola enquanto instituição educativa vem enfrentando, na atualidade, os paradoxos de outras instituições. Como dizia Arendt (1992), ela tem uma função conservadora de transmissão das tradições, ao mesmo tempo que é desafiada a pensar numa formação crítico-transformadora, ou seja, situa-se entre o "passado e o futuro". Buscar um equilíbrio entre essas duas funções não é tarefa fácil, mas é o desafio que emerge das reflexões propostas por Charlot, entre outros, bem como das contribuições de experiências de educação construídas fora do espaço escolar. São experiências que se desenvolvem em espaços educativos organizados, mas não subordinados às rigorosas regras institucionais existentes na maioria das escolas.

Movimentos e organizações sociais populares, bem como experiências construídas no âmbito de escolas, fornecem elementos significativos para repensar o papel e a função da escola no contexto das sociedades complexas 
(Gohn, 2001). É importante explicitar que essa postura não tem nenhuma pretensão de idolatrar experiências, mas de buscar nelas elementos que contribuam para a ressignificação da escola e ajudem a enfrentar os complexos desafios políticos e pedagógicos que emergem das transformações em curso. São vários elementos que podem ser destacados dessas experiências: a mobilização e a valorização dos sujeitos; a dimensão política do ato pedagógico, ou seja, educar é formar politicamente; a construção de temas geradores que abrem espaços para a incorporação de problemas e questões emergentes; a reestruturação curricular visando a incorporação de temas e problemas próprios dos contextos e das transformações em curso; a reorganização do modelo escolar fordista baseado em tempos fixos e disciplinadores mediante a incorporação de diferentes temporalidades; etc. Esses desafios exigem rupturas com o modelo hegemônico da escola, mas possibilitam ressignificar a escola e os processos pedagógicos ao colocar em pauta questões que as políticas educacionais e a escola, de um modo geral, não têm conseguido equacionar, como a "dualidade de sistemas", ou seja, uma escola para preparar trabalhadores (mão-de-obra) e outra para formar pensadores. A superação dessa dualidade implica repensar as relações entre a escola e a sociedade, bem como pedagogias que deem conta dos complexos desafios atuais. 0 título da obra de Arroyo (2012), "outros sujeitos, outras pedagogias", expressa bem esses desafios.

As experiências que estão sendo construídas pelas Escolas Itinerantes do Movimento Sem Terra (MST), por exemplo, podem contribuir nesse avanço. Elas possuem um formato e uma organização menos burocrática do que as demais escolas. Há uma pedagogia que é denominada "da terra"; os conhecimentos são organizados por temas geradores, ou seja, partem obrigatoriamente de questões e problemas existentes na realidade. Apoiados em ideias de Paulo Freire, Florestan Fernandes, Makarenko, Pistrak, entre outros, constroem, com a participação efetiva dos sujeitos envolvidos, temas geradores que estão vinculados aos contextos e às realidades dos alunos e suas famílias. Assim, a organização curricular deixa de ser responsabilidade exclusiva dos gestores e professores e passa a ser partilhada com os pais, alunos e as liderança do movimento. Dessa forma, segundo Luciano (2008, p. 79), os conteúdos são “construídos no decorrer da prática educativa, servindo-se dos acontecimentos produzidos historicamente, que são problematizados e contextualizados a partir das experiências de luta". A organização pedagógica envolve os alunos em tempo integral, o que forçou a reestruturação do calendário escolar, que deixou de ser mera formalidade de 200 dias letivos, conforme prevê a legislação. “A frequência e os horários são fixados a partir do compromisso assumido entre educadores, educandos, comunidade do acampamento, Secretaria de Educação 
e MST" (Luciano, 2008, p. 79). Essa concepção de tempo segue uma lógica diferente de organização da escola convencional por entender que a formação ocorre permanentemente. Tudo o que envolve o acampamento tem a ver com a educação escolar.

De acordo com Haddad e Di Pierro (1994, p. 47), as Escolas Itinerantes propõem-se a fazer uma escola diferente, amparadas nas experiências dos sujeitos e nos problemas existentes em cada contexto, incentivando práticas coletivas de participação, assim como vinculando os conhecimentos com as experiências dos envolvidos. Da mesma forma, Camini (2009, p. 185) traz à tona elementos constitutivos da escola itinerante para evidenciar que essa experiência avança na construção de uma escola diferenciada da maioria existente na atualidade. Para a autora, ela possui práticas formativas que sinalizam para uma nova proposta de formação na medida em que nasce de necessidades reais dos acampados, que se constituem enquanto sujeitos que contestam a ordem instituída, como a que legitima o latifúndio. Entre os vários elementos emergentes dessas experiências, Camini (1999, p. 14) destaca a auto-organização dos educandos. Esse princípio pedagógico é fundamental porque envolve a formação para a autonomia, fato que pressupõe o exercício da organização dos próprios educandos. Para o MST, a auto-organização é compreendida como

[...] o direito que os educandos têm de se organizarem em coletivos, com tempo e espaço próprio, para analisar e discutir as suas questões, elaborar propostas e tomar as suas decisões em vista de participar como sujeitos da gestão democrática, do processo educativo e da escola como um todo. (MST, 1999, p. 14)

A autogestão é um exercício político que pode produzir novas e originais formas de exercício do poder e de organização das instituições, no caso a escola. Ao elaborar propostas, avaliar e promover ações coletivas, a escola promove uma gestão compartilhada nos processos decisórios. A escola não é uma instituição deslocada do contexto social, mas é parte fundamental da constituição da própria comunidade e, no caso, do movimento. Neste sentido, a democracia não é um conceito vazio nem meramente incluído em alguns conteúdos curriculares, mas se efetiva nas diversas práticas que perpassam 0 fazer pedagógico da escola.

Nessas experiências, a relação entre escola e contexto social ocorre de modo intenso e sistemático. Ao aprofundar o diálogo entre a escola e a sociedade, o conhecimento sistematizado ganha vitalidade e sentido. Os temas geradores brotam do contexto social, econômico, político e cultural por meio de pesquisas que possibilitam a apreensão de temas e questões significativas para os sujeitos e para a construção do conhecimento escolar. 
Os temas geradores possibilitam uma transversalidade entre saberes e diferentes disciplinas e/ou campos de conhecimento. Eles são selecionados em função da relevância, da transdisciplinaridade e de se constituírem em problemas significativos. Para dar conta desses desafios, é fundamental uma metodologia interdisciplinar e/ou a transdisciplinar, bem como um planejamento pedagógico coletivo. Neste contexto, a formação continuada dos professores é essencial e tem de envolver o planejamento, a organização das atividades, os estudos e as formas de avaliação.

As relações entre a escola e a sociedade têm de produzir vínculos mobilizadores de práticas pedagógicas que promovam conhecimentos, diálogos e reflexões críticas sobre a cultura e os valores disseminados pelos grupos hegemônicos, bem como a valorização das experiências dos sujeitos. As experiências sociais são constitutivas do trabalho pedagógico escolar. No entanto, elas não podem ser tomadas como dados, mas precisam ser problematizadas visando a construção e a desconstrução da realidade percebida. Como diz Dubet (1994, p. 95-98), esses processos acontecem não porque o indivíduo está fora do social, mas porque a sua experiência se inscreve em registros múltiplos e não congruentes, e a ação não é redutível a um programa único, ou seja, os sujeitos não são determinados pelo sistema, mas possuem capacidade de posicionar-se criticamente frente a ele e transformá-lo. Nesse movimento reflexivo, abre-se possiblidade para uma compreensão crítica das contradições socioeconômicas e culturais, bem como para se pensar em possibilidades de transformação, mesmo tendo consciência das resistências existentes, especialmente no contexto das sociedades complexas. A escola torna-se, então, um espaço de construção de novas relações com o saber e de reflexões críticas e transformadoras.

Ao aprofundar o diálogo entre escola e sociedade, o conhecimento construído na escola ganha novo sentido. As relações orgânicas entre a escola e a sociedade têm de produzir vínculos mobilizadores de práticas pedagógicas que promovem conhecimento, diálogo e reflexão crítica sobre a cultura e os valores disseminados pelos grupos hegemônicos, bem como valorizar as experiências populares. Experiências educativas como as construídas pelas Escolas Itinerantes possibilitam pensar na função social da escola, que é a de contribuir para uma compreensão das complexas relações existentes e das transformações em curso na sociedade atual.

As possibilidades de aprofundar os vínculos entre a escola e o contexto onde ela está inserida exigem várias transformações. Em primeiro lugar, é fundamental uma abertura para o diálogo com os movimentos e organizações existentes no âmbito da sociedade civil, o que envolve o reconhecimento dos limites da escola no contexto das sociedades complexas, bem como a disposição 
de mudar. É fundamental uma atitude de diálogo entre a escola e as experiências pedagógicas que são produzidas em espaços não formais, bem como uma abertura para a reestruturação curricular. Nesse sentido, tanto as organizações e os movimentos sociais populares quanto a escola podem superar um conjunto de desafios atuais. Enquanto a escola se portar como transmissora de verdades e de conhecimentos conclusos, não há possibilidade para novas relações com o saber.

Os grandes desafios emergentes das sociedades complexas exigem esforços coletivos e processos educacionais dinâmicos que consigam captar e problematizar as realidades e suas contradições, bem como produzir novas formas de apropriação e reconstrução do conhecimento. 0 grande problema identificado por Charlot nas pedagogias tradicional e moderna, a separação entre a escola e sociedade, pode ser enfrentado com a efetivação de novas relações com o saber. Daí o desafio pedagógico de criar espaços para o diálogo, a formação de cidadãos politizados e a abertura para as mudanças necessárias. A escola tem uma importante contribuição na formação democrática. A democracia, como diz Dewey (1979), não é inerente à natureza humana, mas tem de ser construída pela educação.

\section{Considerações finais}

Muito mais do que concluir, pretendemos, nessas considerações finais, sistematizar algumas questões que foram desenvolvidas no texto e apontar alguns desafios para a prática educativa escolar. Uma primeira questão diz respeito à compreensão do que constitui as sociedades complexas. Tentamos argumentar que a complexidade das sociedades não é exclusiva do nosso tempo. No entanto, há um conjunto de elementos que emerge na atualidade e complexifica a sociedade e suas instituições com profundas implicações na formação dos indivíduos e nas formas de socialização. Ao mesmo tempo que formas de pensamento pósmetafísico provocam mudanças substanciais, crescem novas formas de pensar metafísico fortemente influenciadas por interpretações teológicas de mundo, muitas das quais fundamentalistas, dogmáticas e conservadoras. Pensar em sociedades complexas implica não só trazer à tona elementos de caráter empírico, mas também colocar em pauta questões de natureza teórica, epistemológicas e metodológicas. Não há como dar conta de contextos complexos sem a mediação de referenciais que possibilitem interrogar as realidades do modo profundo. Referenciais deterministas não dão conta das sociedades complexas que são plurais em suas expressões socioculturais, políticas e pedagógicas. 
A complexidade social se expressa no contexto atual por meio da emergência de inúmeros recursos tecnológicos que aceleram significativamente as comunicações, disponibilizando quantidades expressivas de informações que vão além de qualquer capacidade individual e transformam as relações econômicas e culturais. Essa multiplicidade de possibilidades ganha formulações teóricas e epistêmicas múltiplas. Enquanto em outros períodos históricos predominava uma ou outra tradição epistêmica, no contexto atual convivem muitas tradições intelectuais, inclusive no âmbito das mesmas instituições educacionais. Não dá para negar que estamos vivendo num período histórico em que a democratização e a pluralidade de ideias, valores, comportamentos, teorias e paradigmas é uma realidade.

Com base nessas considerações, quais os desafios decorrentes para a escola e para as práticas educativas? Um primeiro desafio é romper com o histórico enclausuramento da escola em relação à sociedade. Ela está sendo desafiada a pensar criticamente as opções que estão sendo feitas pela sociedade, as questões relativas aos valores democráticos e participativos, as formas de sustentabilidade, o reconhecimento da diversidade de gênero, as múltiplas culturas e as diversas experiências de produção da subsistência, etc. Em segundo, é fundamental dar visibilidade às experiências pedagógicas alternativas. A Escola Itinerante é uma dessas experiências, mas existem outras. Originada de demandas sociais, foi se constituindo como alternativa à escola tradicional. Mesmo com todos os entraves enfrentados, ela consegue problematizar um conjunto de questões nas quais o modelo de escola hegemônico encontra inúmeras dificuldades, entre elas a explicitação da dimensão política da ação pedagógica, a superação de conteúdos alienantes mediante a construção de temas geradores, a definição objetiva dos fins da educação que é o empoderamento dos sujeitos nas lutas pela sobrevivência e na participação política, a formulação de princípios constitutivos de uma nova pedagogia.

A reflexão sobre experiências educativas crítico-transformadoras deve incidir sobre as instituições existentes e ressignificar esses espaços. Como diz Charlot (2002, p. 30), é fundamental uma "pedagogia de riscos" capaz de questionar valores, ideias e práticas cristalizadas. A ressignificação da escola tem de enfrentar a passividade e a indiferença, por meio de conteúdos e pedagogias que contribuam para uma formação humana crítica. As opções pedagógicas têm de desafiar professores e alunos a constituírem-se como sujeitos. Como decorrência, é fundamental repensar também o currículo, as formas de avaliação e a formação continuada de professores. São desafios históricos, mas que se intensificam quando pensados nos contextos das sociedades complexas atuais. 


\section{Referências}

ARROYO, Miguel G. Outros sujeitos, outras pedagogias. Petrópolis: Vozes, 2012.

ARENT, Hannah. A Crise na Educação. In: ARENT, Hannah. Entre o passado e o futuro. 3.ed. pp. 221-247. São Paulo: Perspectiva, 1992.

ANTUNES, Ricardo. Os sentidos do trabalho: ensaio sobre a afirmação e a negação do trabalho. São Paulo: Boitempo Editorial, 1999.

. O caracol e sua concha: ensaios sobre a nova morfologia do trabalho.

São Paulo: Boitempo, 2005.

ANTUNES, Ricardo; BRAGA, RUY (Orgs.). Infoproletários: degradação real do trabalho virtual. São Paulo: Boitempo, 2009.

BAUMAN, Zygmunt. A sociedade individualizada: vidas contadas e histórias vividas. Rio de Janeiro: Jorge Zahar, 2008.

BENJAMIN, Walter. Sobre o conceito de história. In: BENJAMIN, Walter. Magia e técnica, arte e política. 7. ed. (Obras Escolhidas, v.1), pp. 222-232. São Paulo: Brasiliense, 1994.

BOURDIEU, Pierre; PASSERON, Jean Claude.A reprodução: elementos para uma teoria do ensino. 2.ed. Rio de Janeiro: Francisco Alves, 1982.

CAMINI, Isabela. Escola Itinerante: na fronteira de uma nova escola. São Paulo: Expressão Popular, 2009.

CHARLOT, Bernard. Mistificação pedagógica. Rio de Janeiro: Zahar editores, 1979.

Relação com a escola e o saber nos bairros populares. Revista Perspectiva, v.20, pp. 17-34, jul./dez. 2002.

CHARLOT, Bernard. Relações com o saber na sociedade contemporânea: reflexões antropológicas e pedagógicas. In: CENCl, Ângelo Vitório; DALBOSCO, Cláudio Almir; MÜHL, Eldon Henrique (Orgs.). Sobre filosofia e educação: racionalidade, diversidade e formação pedagógica. pp. 81-100. Passo Fundo: UPF Editora, 2009. COMTE, Augusto. Curso de filosofia positiva. In: Os pensadores: Comte. pp. 1-39. São Paulo: abr. 1978..

DESCARTES, René. Discurso do método: regras para a direção do espírito. São Paulo: Martin Claret, 2003.

DEWEY, John. Democracia e educação: introdução à filosofia da educação. 4.ed. São Paulo: Nacional, 1979.

DURKHEIM, Émile. Educação e sociologia. 11.ed. São Paulo: Melhoramentos, 1978. . As regras do método sociológico. 14.ed. São Paulo: Companhia Editora Nacional, 1990.

ECO, Umberto. O nome da Rosa. Rio de Janeiro: Record, 1986.

FRANCA, Leonel. O Método Pedagógico dos Jesuítas: o "RatioStudiorum". Rio de Janeiro: Livraria Agir Editora, 1952. 
GINZBURG, Carlo. O queijo e os vermes: o cotidiano e as ideias de um moleiro perseguido pela inquisição. 3.ed. São Paulo: Companhia das Letras, 2002.

GOHN, Maria da Glória. História dos movimentos e lutas sociais: a constituição da cidadania dos brasileiros. 2.ed. São Paulo: Loyola, 2001.

HADDAD, Sérgio; PIERRO, Maria Clara Di. A educação no movimento dos trabalhadores rurais sem terra em Bagé e Sarandi (RS). Brasília: Instituto Nacional de Estudos e Pesquisas Educac, 1994.

ILLICH, Ivan. Sociedade sem escola. 7.ed. Petrópolis: Vozes, 1985.

LUCIANO, Charles Luiz Policena. Escola itinerante: uma análise das práticas educativas do MST no contexto. Santa Cruz, EdUnisc, 2008.

MST. Crianças em movimento: as mobilizações infantis no MST. São Paulo: Peres, 1999.

ROUSSEAU, Jean-Jacques. Do contrato social. 4.ed. (Os pensadores, v. I). São Paulo: Nova Cultural, 1987.

SANTOS, Boaventura de Sousa. Introdução a uma ciência pós-moderna. Rio de Janeiro: Graal, 1989.

SANTOS, Boaventura de Sousa (Org.). Conhecimento prudente para uma vida decente: um discurso sobre as ciências revisitado. São Paulo: Cortez, 2004.

SANTOS, Boaventura de Sousa; MENESES, Maria Paula (Orgs.). Epistemologias do Sul. Editora Cortez, 2010.

SAVIANI, Dermeval. Escola e democracia. 9.ed. São Paulo: Cortez, 1989.

Recebido em março de 2014

Aprovado em junho de 2014

Telmo Marcon é doutor em História Social pela Pontifícia Universidade Católica de São Paulo (PUC/SP) e pós-doutor em Educação Intercultural pela Universidade Federal de Santa Catarina (UFSC). É professor e pesquisador no Programa de Pós-Graduação em Educação da Universidade de Passo Fundo (PPGEDU/UPF). E-mail: telmomarconagmail.com

Consuelo Cristine Piaia é mestre em Educação pelo Programa de Pós-Graduação em Educação da Universidade de Passo Fundo (UPF) e doutoranda em Educação no PPGEDU/UPF. E-mail: 24244वupf.br 